\title{
Research on Tourism Information System Based on webGIS Technology -- Taking Hangzhou as an example

\author{
Xifeng $\mathrm{Li}^{1, \mathrm{a}}$, Xuemei Ma ${ }^{2, \mathrm{~b}}$, Qingshuang Zhao ${ }^{3, \mathrm{c}}$ \\ ${ }^{1,3}$ School of Architecture and Civil Engineering, Liaocheng University, Liaocheng 252059, China \\ ${ }^{2}$ School of Environment and Planning, Liaocheng Unversity, Liaocheng 252059, China \\ aemail: lixifeng321@163.com, bemail: \\ remotesensing_ma@yahoo.com.cn, 'email:zhaoqingshuang@lcu.edu.cn
}

Keywords: GIS technology; Tourism information system; Geographic information system; Component GIS; Tourism resources

\begin{abstract}
With social progress and economic development, people's living level gradually improve, tourism has become an essential part of modern people's life. At present, many developed countries of the tourism informationization level has reached a higher level, and the informationization development of tourism in China is still in its primary stage. This article is based on B/S and C/S architecture and tourism information system and the theoretical basis of geographic information system, in hangzhou, for example, applying GIS technology to develop tourism management, planning, decision-making, analysis and query, and other functions in a body, has a good visual effect of tourism information system, so as to promote the development of tourism informatization in our country.
\end{abstract}

\section{Introduction}

Based on WebGIS provides new ideas to realize the informationization of tourism, WebGIS Application in tourism advantage is mainly reflected in: WebGIS with vivid graphic language to express abstract spatial geographic data ${ }^{[1]}$, so that more abundant visual expression of tourism information; WebGIS technology can realize socialization of tourism information sharing, the tourist information can in the world timely and quickly released ${ }^{[1]}$. And can facilitate the management of tourism information in a timely manner to update and management, to promote the modernization of tourism management.

\section{System design}

\section{Overall system design}

Information management system with MapX secondary development platform, using Delphi language programming technology development, to achieve a set of tourism information data management and application in one of the tourism information system ${ }^{[6-8]}$, including data input, renewal, management, graphic display, query and analysis, spatial decision making for managers and for tourists to provide more convenient service

\section{System function design}

(1) data input and update. Tourism information database is the core of tourism information system, due to the tourism information is constantly changing, which requires the management in a timely manner to obtain travel information input to the tourism database, ${ }^{[2]}$ to ensure the tourism information system with real-time.

(2) map display and control. System can display city traffic tourist map, map of the city and other thematic maps, also can display images, sound, animation and other multimedia information, on the map can be to enlarge, narrow, roaming, object selection and map output basic operation.

(3) query function. System to achieve from the properties to graphics, from the graphics to the properties of the two-way query function. Through the query function, visitors can easily access to attractions and service facilities and other tourism related information. ${ }^{[3]}$ 
(4) analysis function. Through the analysis of the function, location and location between the distance measurement and drawing on a regional area on the map, the shortest path analysis function $^{[4]}{ }^{[5]}$ helps the user to choose the appropriate tour route, to meet the needs of tourists of different ${ }^{[5]}$.

\section{System detailed design and function realization}

\section{Requirement analysis}

The data of Hangzhou tourism information system mainly involves spatial data, attribute data and multimedia data ${ }^{[7] .}$ Spatial data is a representation of the spatial position of tourism resources of relevant data, such as scenic spots of the geographical location, boundaries, transportation, water and other; attribute data is data describing the tourism resources, such as name and characteristics of the attractions; multimedia data including and tourism resources related to some documents, pictures, audio, animation and other.

\section{Structure design}

(1) conceptual structure design.

In this design, the spatial data is stored in MapInfo's table structure. The attribute database and multimedia database are constructed with Sever SQL two, and the 2005 are integrated in MapX and Delphi environment.

Spatial database design using the map after vector quantization is composed of three parts of point, line and plane, tourism information system of spatial data by the basic geographic data and thematic data of two types of data, data base including city administrative region, roads, water systems, organs of the resident and data and professional data including attractions, accommodation, catering, transportation and other data. ${ }^{[5]}$

Table 1 spatial database design

\begin{tabular}{|c|c|c|c|}
\hline spatial data & Layer name & Layer description & Element category \\
\hline \multirow{4}{*}{ Basic data } & Residential points & Residential points & Point \\
\cline { 2 - 4 } & River system & Rivers & Plane \\
\cline { 2 - 4 } & lake & lake & Plane \\
\cline { 2 - 4 } & Road & Highway railway & Linear \\
\cline { 2 - 4 } & Greenland & Green land & Plane \\
\hline \multirow{5}{*}{ Thematic data } & Scenic spot & Scenic spot & Point \\
\cline { 2 - 4 } & Accommodation & hotel & Linear \\
\cline { 2 - 4 } & traffic & Bus route & Point \\
\cline { 2 - 4 } & Shopping & Market & Point \\
\cline { 2 - 4 } & education & School scientific & research \\
\hline
\end{tabular}

Attribute database design. Tourism information system attribute data is the description and description of the tourism resources and the attribute data of the system mainly includes tourism resources in Hangzhou, tourism facilities and service aspects of the data, including the attribute data and multimedia data. For example, its attribute data is designed as follows:

Table 2 database attribute design table

\begin{tabular}{|c|c|c|c|c|c|}
\hline Field name & Field type & length & Whether to be empty & Distinguish & Field meaning \\
\hline ID & int & 4 & \begin{tabular}{l|l} 
& $\mathrm{N}$ \\
\end{tabular} & Primary key & sequence \\
\hline name & varchar & 255 & $\mathrm{~N}$ & & Name \\
\hline address & varchar & 255 & $\mathrm{~N}$ & & address \\
\hline telephone & varchar & 50 & $\mathrm{~N}$ & & Telephone \\
\hline introduce & varchar & 2000 & $\mathrm{~N}$ & & $\begin{array}{l}\text { brief } \\
\text { introduction }\end{array}$ \\
\hline
\end{tabular}

(2) logical structure design. The main task of the logical structure design phase is to transform the conceptual structure model into relational data model. When converting the conceptual structure model into relational data model, the relationship between the entities is actually transformed into a 
two-dimensional relationship table. In the design of the relationship model, we should follow the principle of "independent relation independent expression ${ }^{[6] "}$.

(3) physical structure design. Design to determine the physical structure of the database, and then makes an evaluation on the physical structure of time and space efficiency, if the evaluation results are in accord with the requirements of the original design can be turned to the physical implementation of the, if not in line with the requirements of the original design, modify or re design of physical structure, may even return to further modify the logical structure model. ${ }^{[4]}$

After the database physical structure design is completed, the database is established according to the information of the storage scheme and the detailed information of the various tables. In the database implementation phase to complete the database structure definition, data entry database, write and debug program, etc.. DDL definition of database structure, database command using the database management system, the establishment of user corresponding data structure.

\begin{tabular}{|c|c|c|c|c|c|c|c|c|c|c|c|}
\hline \multirow{2}{*}{ 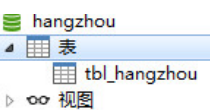 } & $\equiv$ & \multicolumn{4}{|c|}{ 甲新建 回保存 阻另存为 } & \multicolumn{2}{|c|}{ 严添加栏位 + 豆插入栏位 } & \multirow[t]{2}{*}{$\ominus$ 直删除栏位 } & \multirow[t]{2}{*}{ 主䋖 } & \multirow[t]{2}{*}{ 个上移 } & \multirow{2}{*}{ む下移 } \\
\hline & 栏位 & 索引 & 外䋖 & 触发器 & 选项 & 注释 & SQL 预览 & & & & \\
\hline \multirow{7}{*}{ 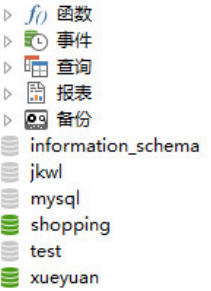 } & \multicolumn{5}{|l|}{ 名 } & \multicolumn{2}{|c|}{ 类型 } & 长度 & 小数点 & 不是 null & \\
\hline & \multicolumn{5}{|c|}{ id } & \multicolumn{2}{|c|}{ int } & 4 & 0 & 四 & $P_{1}$ \\
\hline & \multicolumn{5}{|c|}{ name } & \multicolumn{2}{|c|}{ varchar } & 255 & 0 & $\square$ & \\
\hline & \multicolumn{5}{|c|}{ address } & \multicolumn{2}{|c|}{ varchar } & 255 & 0 & $\square$ & \\
\hline & \multicolumn{5}{|c|}{ telephone } & \multicolumn{2}{|c|}{ varchar } & 255 & 0 & $\square$ & \\
\hline & \multicolumn{5}{|c|}{ introduce } & \multicolumn{2}{|c|}{ varchar } & 255 & 0 & $\square$ & \\
\hline & & & & & & & & & & & \\
\hline
\end{tabular}

Figure 1 database

After the database is put into operation, the management personnel should timely adjust and maintain the database according to the changes of the application environment.

\section{Login function}

Using Windows style interface, including the menu bar, toolbar, status bar, map display window, and navigation window, etc. most of the few, the overall layout of the interface is simple, beautiful appearance, be clear at a glance, and adopt the easy for users to understand the text description of the interface language, to facilitate human-computer interaction.

\section{Query function}

Through the name of the object query object in the map of the location and other attributes of information and multimedia information, the dialog box as shown below:

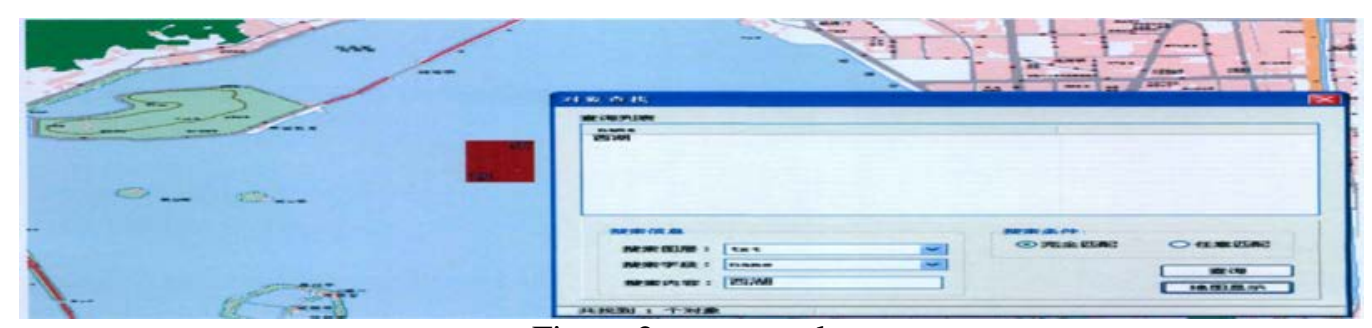

Figure 2 query results

\section{Analysis function}

By using two simple analysis function is realized by Delphi Programming MapX, i.e. two or more points of distance measuring and the shortest path analysis function.

Shortest path analysis. Tourists can travel through the tourist information system to provide the shortest path analysis function to obtain the best travel routes between two points, namely, the shortest route to the lowest fare.

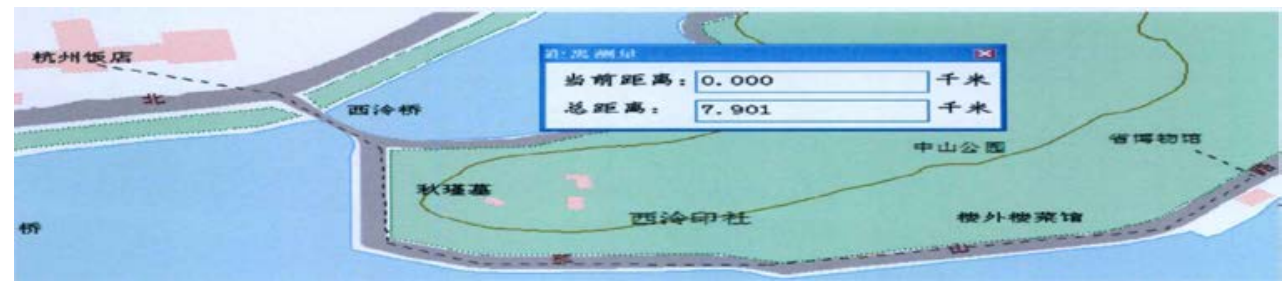

Figure 3. The distance between two points 


\section{Tourism information management function}

To the Shangri La Hotel, Hangzhou as an example, if to Shangri La Hotel information submitted to the system, only the hotel name, contact telephone number, specific address, introduction input information corresponding to the text box, by clicking on the selected video button select the relevant video where the directory submission of new information. If users log on to the system, the program will close the information management function, the operation of the information is not available.

\section{Conclusion}

Taking Hangzhou as a case study construction of tourism information system of WebGIS based on, for tourists to travel provides a convenient, but also facilitate the management personnel resource management, can fast search the attractions, and for Hangzhou further development of tourism resources, resources management and tourism economic development can provide great help, then can improve the visibility of Hangzhou.

\section{Acknowledgement}

In this paper, the research was sponsored by Research project of science and technology in the field of cultural heritage protection of the State Administration of cultural heritage (Project No. 2013 - YB - HT - 007) ,The natural science fund of Shandong Province (fund No.ZR2010DQ018)and Funding for young teachers' growth plan in Shandong Province.

\section{References}

[1] Huang Xiaoting. The research progress of tourism based on [J]. Technology in China GIS geography and Geographic Information Science,2009,(04):79-99.

[2] Hao Suo, Chen Shi. The present situation of tourism industry [M]. Shaanxi: people press,2000.23-25.

[3] Li Yuliang, Tang Hai. Study on the overall design of the tourist oriented geographic information system [J]. science and technology information,2012,(25):165-166.

[4] Wang Fengling, Xing Ting, Wang Guofeng, Li Yu. The development of the information management system of the GIS highway landscape [J]. micro computer information,2011, (10):40-43.

[5] Jia Xueshan, Wu Fenghua, Hou Jinliang. Research and implementation of [J]. based on the GIS technology of the tourist accommodation and catering information system Jia Xueshan, Wu Fenghua, Hou Jinliang. Research and implementation of [J]. based on the GIS technology of the tourist accommodation and catering information system,2016,(03):133-135.

[6] hejun. Design of integrated service platform for Tourist Attractions Based on GISJ]. Science and technology information,2010,(17):428-429.

[7] Wang Jie, Huang Yongli. Design of integrated service platform for tourism scenic spots based on GIS [J].Journalof light industry (NATURAL SCIENCE EDITION), ,2010,(03):114-124.

[8] Jia Fei, Zhang Xiaofeng, Pang Institute. Tourism information system based on [J]. GIS China based on Information Technology2010.(23):114-124. 